\title{
Activity of Demethylation Inhibitor Fungicide Metconazole on Chinese Fusarium graminearum Species Complex and Its Application in Carbendazim-Resistance Management of Fusarium Head Blight in Wheat
}

\author{
Yabing Duan, ${ }^{1,2}$ Xian Tao, ${ }^{1}$ Huahua Zhao, ${ }^{1}$ Xuemei Xiao, ${ }^{1}$ Meixia Li, ${ }^{1}$ Jianxin Wang,,${ }^{1,2}$ and Mingguo Zhou ${ }^{1,2, \dagger}$ \\ ${ }^{1}$ College of Plant Protection, Nanjing Agricultural University, Nanjing, 210095, China; and ${ }^{2}$ State \& Local Joint Engineering \\ Research Center of Green Pesticide Invention and Application, Nanjing, 210095, China
}

\begin{abstract}
Fusarium graminearum species complex (FGSC), causing Fusarium head blight (FHB) of wheat, has species-specific geographical distributions in wheat-growing regions. In recent years, benzimidazole resistance of FHB pathogens has been largely widespread in China. Although the demethylation inhibitor fungicide metconazole has been used for FHB control in some countries, no information about metconazole sensitivity of Chinese FHB pathogen populations and efficacy of metconazole in FHB control in China is available. In this study, the sensitivity of FGSC to metconazole was measured with 32 carbendazim-sensitive strains and 35 carbendazim-resistant strains based on mycelial growth. The $50 \%$ effective concentration values of 67 strains were normally distributed and ranged from 0.0209 to $0.0838 \mu \mathrm{g} \mathrm{ml}^{-1}$, with a mean of $0.0481 \pm$ $0.0134 \mu \mathrm{g} \mathrm{ml}^{-1}$. No significant difference in metconazole sensitivity was observed between carbendazim-sensitive and -resistant populations. An interactive effect of metconazole and phenamacril, a novel cyanoacrilate fungicide approved in China against Fusarium spp., in inhibiting mycelial growth showed an additive interaction at different ratios. Furthermore, field trials to evaluate the effect of metconazole and metconazole + phenamacril treatments in FHB control, deoxynivalenol

(DON) production, and grain yields were performed. Compared with the fungicides carbendazim and phenamacril currently used in China, metconazole exhibits a better efficacy for FHB control, DON production, and grain yields, and dramatically reduces use dosages of chemical compounds in the field. The mixture of metconazole and phenamacril at ratios of 2:3 and 1:2 showed the greatest efficacy for FHB control, DON production, and grain yields among all the fungicide treatments but its use dosages were higher in comparison with metconazole alone. In addition, FHB control, grain yields, and DON levels were significantly correlated with each other, showing that visual disease indices can be used as an indicator of grain yields and DON contamination. Meanwhile, the frequency of carbendazim-resistant alleles in $F$. graminearum populations was dramatically reduced after metconazole and phenamacril alone and the mixture of metconazole and phenamacril applications, indicating that metconazole and a mixture of metconazole and phenamacril can be used for carbendazim resistance management of FHB in wheat. Overall, the findings of this study provide important data for resistance management of FHB and reducing DON contamination in wheat grains.
\end{abstract}

Fusarium head blight (FHB), caused by the Fusarium graminearum species complex (FGSC), is a devastating fungal disease in wheat and other small grain cereals all over the world, leading to serious losses of grain yields and quality (McMullen et al. 1997; Parry et al. 1995). In recent years, the greatest concern for FHB has become the presence of high levels of mycotoxins. FGSC can produce a series of trichothecene mycotoxins in infected grains, including deoxynivalenol (DON), 3-acetyl-DON, 15-acetyl-DON, and nivalenol, threatening food safety and human and animal health (Bottalico and Perrone 2002; Placinta et al. 1999). Members of FGSC, a complex that includes at least 16 distinct and cryptic species, have speciesspecific geographical distributions in different wheat-growing regions (O'Donnell et al. 2008; Yli-Mattila et al. 2009). Previous studies reported that FGSC causing FHB in China mainly includes $F$. asiaticum and $F$. graminearum, and $F$. asiaticum is the dominant population, especially in the Yangtze-Huaihe River basin and the middle and lower reaches of the Yangtze River (Hao et al. 2017; Qiu and Shi 2014; Zhang et al. 2012, 2013).

${ }^{\dagger}$ Corresponding author: M. Zhou; E-mail: mgzhou@njau.edu.cn

Funding: This work was supported by the National Key Research and Development Program of China (2016YFD0200503-04) and the National Natural Science Foundation of China (31772190).

The author(s) declare no conflict of interest.

Accepted for publication 23 November 2018.

(c) 2019 The American Phytopathological Society
Because of the limited resistant gene resources, chemical control has always been a primary strategy for managing FHB. However, the long-term and extensive use of chemical compounds causes the emergence of fungicide resistance in FHB pathogens. In China, carbendazim, a benzimidazole fungicide, has been widely applied for controlling FHB since the 1970s (Yuan and Zhou 2005). In recent years, the carbendazim-resistant field population in FHB pathogens has been increasing under the high selective pressure of carbendazim, resulting in the failure of FHB control (Duan et al. 2014). Phenamacril, a Fusarium-specific fungicide, belongs to novel cyanoacrylate fungicides and has been applied to control FHB in China (Chen et al. 2008, 2011). However, our previous studies indicated that phenamacril has a high risk of resistance development in $F$. graminearum (Chen et al. 2011). Therefore, the development of novel fungicides with high activity is urgent for resistance management of FHB.

Metconazole belongs to the demethylation inhibitor (DMI) fungicides (Ito et al. 1999). It has been registered in many countries for controlling many fungal diseases in various crops such as wheat leaf rust caused by Puccinia spp., wheat Septoria blotch caused by Zymoseptoria tritici, and wheat powdery mildew caused by Blumeria graminis f. sp. tritici (Magan et al. 2002; Paul et al. 2008, 2010; Spolti et al. 2012; Tateishi et al. 2014). In addition, application of metconazole on FHB control has been reported in wheat-growing regions in several countries, showing a better efficacy in improving FHB control and reducing DON levels in grain (Dardis and Walsh 2000; Tateishi et al. 2010). However, metconazole has not yet been registered in agriculture in China. No information is available on in vitro and in planta effects of metconazole on Chinese FGSC populations, as well as its effects on grain yields and DON accumulation in grain kernels. In this study, to manage carbendazim resistance in F. graminearum, baseline sensitivity of Chinese FGSC populations to metconazole was established. Furthermore, application of metconazole for 
FHB control in wheat, grain yields, and DON contamination was evaluated in field trials. To delay phenamacril resistance development in F. graminearum, interactive effects of metconazole and phenamacril in both carbendazim-sensitive and -resistant populations of $F$. graminearum were measured and application of the mixture of metconazole and phenamacril for FHB control, grain yields, and DON contamination was assessed in field trials. Finally, impact of metconazole and a mixture of metconazole and phenamacril in carbendazim-resistant populations of $F$. graminearum was determined and the correlation of between FHB control, DON levels, and grain yields was analyzed in this study.

\section{Materials and Methods}

Fungal strains and chemical compounds. All of the F. graminearum strains were collected from diseased wheat ears from different geographical areas of Jiangsu Province in China during 2015 and 2016. In total, 32 carbendazim-sensitive strains and 35 carbendazimresistant strains carrying $\beta$-tubulin F167Y were identified by loopmediated isothermal amplification method, as reported by Duan et al. (2014). These strains were obtained by a single-spore method.

Technical-grade metconazole and phenamacril were provided by Jiangsu Sevencontinent Green Chemical Co. Ltd. and the Jiangsu branch of the National Pesticide Research and Development South Center of China, respectively. These fungicides were dissolved in methanol at $10 \mathrm{mg} \mathrm{ml}^{-1}$ as a stock solution. Metconazole formulation (40\%, suspension concentrate [SC]), phenamacril formulation $(25 \%$, $\mathrm{SC}$ ), and carbendazim formulation (50\%, wettable powder [WP]) were purchased from Nanjing Nannong Pesticide Scientific and Technological Development Co. Ltd., Jiangsu Pesticide Institute Co. Ltd., and Zhenjiang Jiansu Pesticide Chemical Co. Ltd., respectively. Technical-grade fungicides were used for mycelial growth sensitivity in vitro. Fungicide formulations were used for field trails.

Metconazole sensitivity testing. Sensitivity tests of $67 \mathrm{~F}$. graminearum strains to metconazole were determined by a mycelial growth inhibition method, as described in previous studies (Duan et al. 2013; Li et al. 2018). Petri dishes ( $90 \mathrm{~mm}$ in diameter) were filled with $15 \mathrm{ml}$ of potato dextrose agar (PDA) containing metconazole at $0,0.0078,0.0156,0.03125,0.0625,0.125$, or $0.25 \mu \mathrm{g} \mathrm{ml}^{-1}$.

Table 1. Concentration gradients used for the sensitivity tests of Fusarium graminearum to metconazole and phenamacril alone and the mixture of metconazole and phenamacril

\begin{tabular}{llllllll}
\hline Fungicide & \multicolumn{7}{c}{ Concentration gradient $\left(\boldsymbol{\mu g ~ m \mathbf { ~ } ^ { \mathbf { - 1 } } )}\right.$} \\
\hline Metconazole (MET) & 0.00625 & 0.0125 & 0.025 & 0.05 & 0.1 & 0.2 & 0.4 \\
Phenamacril (PHE) & 0.025 & 0.05 & 0.1 & 0.2 & 0.4 & 0.8 & 1.6 \\
MET:PHE (8:1) & 0.00625 & 0.0125 & 0.025 & 0.05 & 0.1 & 0.2 & 0.4 \\
MET:PHE (4:1) & 0.00625 & 0.0125 & 0.025 & 0.05 & 0.1 & 0.2 & 0.4 \\
MET:PHE (3:1) & 0.00625 & 0.0125 & 0.025 & 0.05 & 0.1 & 0.2 & 0.4 \\
MET:PHE (2:1) & 0.00625 & 0.0125 & 0.025 & 0.05 & 0.1 & 0.2 & 0.4 \\
MET:PHE (1:1) & 0.00625 & 0.0125 & 0.025 & 0.05 & 0.1 & 0.2 & 0.4 \\
MET:PHE (1:2) & 0.00625 & 0.0125 & 0.025 & 0.05 & 0.1 & 0.2 & 0.4 \\
MET:PHE (1:3) & 0.0125 & 0.025 & 0.05 & 0.1 & 0.2 & 0.4 & 0.8 \\
MET:PHE (1:4) & 0.0125 & 0.025 & 0.05 & 0.1 & 0.2 & 0.4 & 0.8 \\
MET:PHE (1:8) & 0.025 & 0.05 & 0.1 & 0.2 & 0.4 & 0.8 & 1.6 \\
\hline
\end{tabular}

Mycelial plugs (5 mm in diameter) from the margin of a 2-day-old colony were transferred onto PDA plates amended with a series of fungicide concentrations. After incubation for 3 days at $25^{\circ} \mathrm{C}$ in the dark, the diameter of colony was measured and the $50 \%$ effective concentration $\left(\mathrm{EC}_{50}\right)$ was calculated, as previously described (Duan et al. 2013). Three replicates for each concentration of each strain were performed.

Interactive effects of metconazole and phenamacril on mycelial growth. To determine synergetic effects of metconazole and phenamacril on mycelial growth in $F$. graminearum, mycelial plugs from the margins of 2-day-old colonies were placed onto PDA plates amended with a gradient of fungicide concentrations that included a single fungicide (metconazole or phenamacril alone) or both fungicides with ratios of metconazole/phenamacril ranging from $8: 1$ to $1: 8$ (Table 1). After incubation for 3 days at $25^{\circ} \mathrm{C}$, colony diameters were measured, and observed $\mathrm{EC}_{50}$ was calculated as reported in the previous section. Expected $\mathrm{EC}_{50}$ values for the mixtures were calculated according to previous studies (Gisi et al. 1985; Levy et al. 1986). The interactive effects of the two fungicides were assessed by comparison of observed and expected $\mathrm{EC}_{50}$ values, as previously described (Duan et al. 2012; Li et al. 2018). The synergy ratio (SR) was calculated by the ratio of the expected to the observed $\mathrm{EC}_{50}$ values according to previous studies (Gisi et al. 1985; Li et al. 2018).

Application of metconazole in controlling FHB, DON contamination, and grain yields in field trials. To determine effects of metconazole on controlling FHB, DON contamination, and grain yields, field trials were performed at Baimahu farms (Jiangsu Province, China) planted with the susceptible wheat cultivar Huaimai 33 naturally infected with FGSC in 2015 and 2016. Nine treatments, including a no-fungicide control consisted of (i) metconazole (40\%, SC), $75 \mathrm{~g}$ active ingredient (a.i.)/ha; (ii) metconazole (40\%, SC), $150 \mathrm{~g}$ a.i./ha; (iii) metconazole (40\%, SC), $225 \mathrm{~g}$ a.i./ha; (iv) metconazole (40\%, SC), $300 \mathrm{~g}$ a.i./ha; (v) phenamacril $(25 \%$, SC), $225 \mathrm{~g}$ a.i./ha; (vi) phenamacril $(25 \%, \mathrm{SC}), 375 \mathrm{~g}$ a.i./ha; (vii) carbendazim $(50 \%$, WP), $750 \mathrm{~g}$ a.i./ha; (viii) carbendazim (50\%, WP), 1,500 g a.i./ha; and (ix) water control, 750 liters/ha. All of the plots $\left(20 \mathrm{~m}^{2}\right.$ per plot $)$ treated with fungicides were randomly arranged in an experimental field. Three replicate plots for each treatment were performed. The

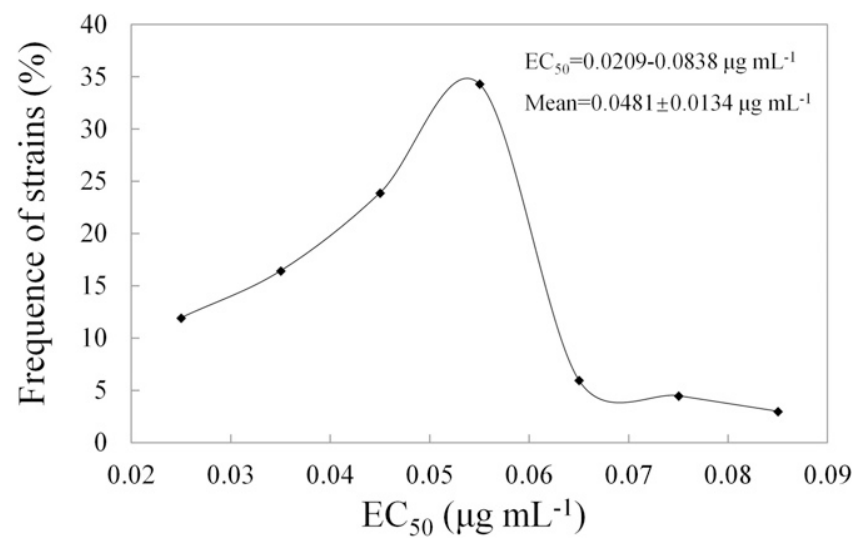

Fig. 1. Sensitivity distribution of 67 Fusarium graminearum isolates to metconazole based on in vitro mycelial growth inhibition. $\mathrm{EC}_{50}=50 \%$ effective concentration.

Table 2. Metconazole sensitivity ranges and distributions of Fusarium graminearum strains used in this study

\begin{tabular}{|c|c|c|c|c|}
\hline \multirow[b]{2}{*}{ Fungal population } & \multicolumn{2}{|c|}{$E_{50}\left(\mu \mathrm{g} \mathrm{ml}^{-1}\right)^{x}$} & \multirow[b]{2}{*}{$95 \%$ FI $^{y}$} & \multirow[b]{2}{*}{$\mathbf{W}$ test $^{\mathrm{z}}$} \\
\hline & Range & Mean & & \\
\hline Carbendazim-sensitive $(n=32)$ & $0.0238-0.0838$ & $0.0484 \pm 0.0140 \mathrm{a}$ & $0.0434-0.0534$ & $P=0.793$ \\
\hline Carbendazim-resistant $(n=35)$ & $0.0209-0.0801$ & $0.0479 \pm 0.0132 \mathrm{a}$ & $0.0343-0.0534$ & $P=0.809$ \\
\hline All strains $(n=67)$ & $0.0209-0.0838$ & $0.0481 \pm 0.0135 a$ & $0.0448-0.0514$ & $P=0.498$ \\
\hline
\end{tabular}

${ }^{\mathrm{x}}$ For each fungal population, means \pm standard deviations were calculated from the test isolates and the same lowercase letter indicates statistically no significant differences $(P<0.05)$ according to the least significant difference test.

y $\mathrm{FI}=$ fiducial interval.

${ }^{\mathrm{z}}$ Shapiro-Wilk test for normal distribution. $P>0.05$ assumed to be normally distributed. 
fungicides were first sprayed with electric sprayer (SX-MD16H; Zhongbao) at the beginning of anthesis and then sprayed a second time 5 days later. After about 15 days, FHB symptoms (200 ears/ plot) were assessed using the following key values: $0=$ no symptoms and $1=<25,3=25$ to $50,5=>50$ to 75 , and $7=>75 \%$ of total spikelets of wheat ears covered with symptoms. Disease index and control efficacy were calculated using the following formulas (Duan et al. 2018): disease index $=\left[\sum\right.$ (key value $\times$ number of wheat ears for the corresponding key value)/(the highest key value $\times$ number of total wheat ears $)] \times 100$; and control efficacy $(\%)=[($ disease index for the control - disease index for fungicide treatment)/disease index for the control] $\times 100$.

Application of the mixture of metconazole and phenamacril in controlling FHB, DON contamination, and grain yields in wheat field trials. To further evaluate the application of the mixture of metconazole and phenamacril in FHB control, DON contamination, and grain yields, the ratios 1:4, 1:3, 1:2, and 2:3 of metconazole/ phenamacril were selected and assessed for controlling FHB in field trials. Nine treatments for the mixture of metconazole and phenamacril were (i) metconazole $(40 \%, \mathrm{SC})+$ phenamacril $(25 \%, \mathrm{SC}), 36+$ $144 \mathrm{~g}$ a.i./ha; (ii) metconazole $(40 \%, \mathrm{SC})+$ phenamacril $(25 \%, \mathrm{SC})$, $48+192$ g a.i./ha; (iii) metconazole $(40 \%, \mathrm{SC})+$ phenamacril $(25 \%$, SC), $45+135$ g a.i./ha; (iv) metconazole $(40 \%$, SC) + phenamacril $(25 \%, \mathrm{SC}), 60+180 \mathrm{~g}$ a.i./ha; (v) metconazole $(40 \%, \mathrm{SC})+$ phenamacril $(25 \%, \mathrm{SC}), 60+120 \mathrm{~g}$ a.i./ha; (vi) metconazole $(40 \%, \mathrm{SC})+$ phenamacril $(25 \%, \mathrm{SC}), 80+160 \mathrm{~g}$ a.i./ha; (vii) metconazole $(40 \%$, $\mathrm{SC})+$ phenamacril $(25 \%, \mathrm{SC}), 72+108 \mathrm{~g}$ a.i./ha; (viii) metconazole $(40 \%, \mathrm{SC})+$ phenamacril $(25 \%, \mathrm{SC}), 96+144 \mathrm{~g}$ a.i./ha; and (ix) other treatments, including single fungicide or water control, and next experiment processes were the same as those described in the section above.
Determination of grain yields. Before wheat was harvested, 200 wheat ears for each plot were randomly selected and evaluated for grain yields. The wheat ears were processed with a thresher (KT200; Jindadi) and dried at room temperature. A 100-g sample of dried wheat grains from each plot was arbitrarily selected to determine thousand-grain weight (TGW), as previously described (Zhang et al. 2010). Each plot had three technical replicates.

Determination of DON contamination in grain. As described above, $100 \mathrm{~g}$ of the dried wheat grain for each plot was ground to a powder using a grain mill. Three finely ground subsamples $(20$ $\mathrm{g} /$ subsample) per plot were diluted with sterile, deionized water and assessed for DON content with DON Plate Kit enzyme-linked immunosorbent assay (Jiangsu Wise Science \& Technology Development Co., Ltd.). DON content was calculated by a ratio of DON content to dry wheat powder (milligrams per kilogram).

Measurement of carbendazim-resistant alleles in $F$. graminearum field populations. After FHB symptoms were assessed, 100 diseased wheat ears per plot were randomly selected and the diseased wheat spikelet was used to extract genomic DNA of FHB pathogens, as previously described (Duan et al. 2016). To assess the effect of metconazole and a mixture of metconazole and phenamacril on development of carbendazim-resistant $F$. graminearum field populations, carbendazim-resistant alleles in each plot in field trials were measured by loop-mediated isothermal amplification assays, as reported by Duan et al. (2014).

Statistical analysis. A Shapiro-Wilk test was used to assess normality of $\mathrm{EC}_{50}$ values of carbendazim-resistant and -sensitive populations to metconazole. A Kolmogorov-Smirnov test was used to assess the difference for metconazole sensitivity between carbendazimresistant and -sensitive populations. Multiple comparisons of FHB control, DON levels, or grain yields with the different fungicide treatments were

Table 3. Interactions between metconazole and phenamacril based on inhibition of mycelial growth of carbendazim-sensitive strain S45

\begin{tabular}{|c|c|c|c|c|c|}
\hline \multirow[b]{2}{*}{ Fungicide } & \multirow[b]{2}{*}{ Linear regression equation } & \multirow[b]{2}{*}{$R^{2}$} & \multicolumn{2}{|c|}{$E C_{50}\left(\mu \mathrm{g} \mathrm{ml}^{-1}\right)^{y}$} & \multirow[b]{2}{*}{$\mathbf{S R}^{\mathbf{z}}$} \\
\hline & & & Observed & Expected & \\
\hline Metconazole (MET) & $y=6.8150+1.1490 x$ & 0.9863 & 0.0263 & $\ldots$ & $\ldots$ \\
\hline Phenamacril (PHE) & $y=6.3694+2.0240 x$ & 0.9760 & 0.2106 & $\ldots$ & $\ldots$ \\
\hline MET:PHE (8:1) & $y=6.4676+0.9816 x$ & 0.9899 & 0.0320 & 0.0291 & 0.91 \\
\hline MET:PHE (4:1) & $y=6.4825+0.9905 x$ & 0.9913 & 0.0319 & 0.0319 & 1.00 \\
\hline MET:PHE (3:1) & $y=6.6840+1.0589 x$ & 0.9869 & 0.0257 & 0.0337 & 1.31 \\
\hline MET:PHE (2:1) & $y=6.7146+1.0895 x$ & 0.9915 & 0.0267 & 0.0371 & 1.39 \\
\hline MET:PHE (1:1) & $y=6.3364+0.9385 x$ & 0.9971 & 0.0377 & 0.0468 & 1.24 \\
\hline MET:PHE (1:2) & $y=6.3926+1.1399 x$ & 0.9940 & 0.0600 & 0.0631 & 1.05 \\
\hline MET:PHE (1:3) & $y=6.4469+1.2469 x$ & 0.9924 & 0.0691 & 0.0765 & 1.11 \\
\hline MET:PHE (1:4) & $y=6.4999+1.3067 x$ & 0.9978 & 0.0711 & 0.0877 & 1.23 \\
\hline MET:PHE (1:8) & $y=6.5038+1.4562 x$ & 0.9799 & 0.0927 & 0.1184 & 1.28 \\
\hline
\end{tabular}

${ }^{y} \mathrm{EC}_{50}=50 \%$ effective concentration.

${ }^{\mathrm{z}}$ Synergy ratio $(\mathrm{SR})=$ ratio between expected and observed $\mathrm{EC}_{50}$ values.

Table 4. Interactions between metconazole and phenamacril based on inhibition of mycelial growth of carbendazim-resistant strain R49

\begin{tabular}{|c|c|c|c|c|c|}
\hline \multirow[b]{2}{*}{ Fungicide } & \multirow[b]{2}{*}{ Linear regression equation } & \multirow[b]{2}{*}{$R^{2}$} & \multicolumn{2}{|c|}{$\mathrm{EC}_{50}\left(\mu \mathrm{g} \mathrm{ml}^{-1}\right)^{\mathrm{z}}$} & \multirow[b]{2}{*}{$\mathbf{S R}^{\mathbf{z}}$} \\
\hline & & & Observed & $\overline{\text { Expected }}$ & \\
\hline Metconazole (MET) & $y=5.9661+0.6809 x$ & 0.9865 & 0.0381 & $\ldots$ & $\bar{\ldots}$ \\
\hline Phenamacril (PHE) & $y=6.0625+1.5369 x$ & 0.9994 & 0.2036 & $\ldots$ & $\ldots$ \\
\hline MET:PHE (8:1) & $y=6.5542+1.0215 x$ & 0.9905 & 0.0301 & 0.0419 & 1.39 \\
\hline MET:PHE (4:1) & $y=6.2844+0.8615 x$ & 0.9906 & 0.0323 & 0.0455 & 1.41 \\
\hline MET:PHE (3:1) & $y=6.0574+0.7467 x$ & 0.9868 & 0.0384 & 0.0478 & 1.25 \\
\hline MET:PHE (2:1) & $y=5.6180+0.4478 x$ & 0.9971 & 0.0417 & 0.0523 & 1.25 \\
\hline MET:PHE (1:1) & $y=5.6125+0.4908 x$ & 0.9935 & 0.0565 & 0.0642 & 1.14 \\
\hline MET:PHE (1:2) & $y=5.7319+0.6770 x$ & 0.9864 & 0.0830 & 0.0832 & 1.00 \\
\hline MET:PHE (1:3) & $y=5.8395+0.8420 x$ & 0.9954 & 0.1007 & 0.0976 & 0.97 \\
\hline MET:PHE (1:4) & $y=6.2242+1.1280 x$ & 0.9921 & 0.0822 & 0.1089 & 1.33 \\
\hline MET:PHE (1:8) & $y=6.2277+1.3390 x$ & 0.9947 & 0.1211 & 0.1373 & 1.13 \\
\hline
\end{tabular}

${ }^{\mathrm{y}} \mathrm{EC}_{50}=50 \%$ effective concentration.

${ }^{\mathrm{z}}$ Synergy ratio $(\mathrm{SR})=$ ratio between expected and observed $\mathrm{EC}_{50}$ values. 
carried out with the least significant difference test. Pearson's correlation analysis was used to assess the correlation of FHB control, DON levels, and grain yields.

\section{Results}

Baseline sensitivity of $\boldsymbol{F}$. graminearum to metconazole. Based on mycelial growth inhibition, six or seven single-spore F. graminearum strains (32 carbendazim-sensitive strains and 35 carbendazim-resistant strains) were used to test the sensitivity to metconazole. The $\mathrm{EC}_{50}$ values for carbendazim-sensitive and -resistant strains ranged from 0.0238 to $0.0838 \mu \mathrm{g} \mathrm{ml}^{-1}$ and from 0.0209 to $0.0801 \mu \mathrm{g} \mathrm{ml}^{-1}$, respectively (Table 2). The Shapiro-Wilk test indicated that the distribution of $\mathrm{EC}_{50}$ values was a normal curve for carbendazim-sensitive $(P=0.793)$ and -resistant $(P=0.809)$ strains (Table 2). The $\mathrm{EC}_{50}$ values for all of the test strains $(n=67)$ ranged from 0.0209 to $0.0838 \mu \mathrm{g} \mathrm{ml}^{-1}$, with a mean $\mathrm{EC}_{50}$ value of $0.0481 \pm$ $0.0134 \mu \mathrm{g} \mathrm{ml}^{-1}$, and were normally distributed $(P=0.498)$ (Fig. 1 ; Table 2). In addition, the $\mathrm{EC}_{50}$ values were statistically analyzed

Table 5. Impact of fungicide applications on Fusarium head blight (FHB) control, deoxynivalenol (DON) content, and grain yields in wheat field trials of Baimahu farm in 2015 and $2016^{\mathrm{y}}$

\begin{tabular}{|c|c|c|c|c|c|c|c|}
\hline \multirow[b]{2}{*}{ Fungicide $^{\mathrm{z}}$} & \multirow[b]{2}{*}{ Dose } & \multicolumn{3}{|c|}{2015} & \multicolumn{3}{|c|}{2016} \\
\hline & & FHB control $(\%)$ & DON (mg/kg) & TGW (g) & FHB control $(\%)$ & DON (mg/kg) & TGW (g) \\
\hline MET & 75 & $63.11 \pm 3.95 \mathrm{i}$ & $1.19 \pm 0.06 \mathrm{~d}$ & $39.17 \pm 0.48$ ef & $65.55 \pm 4.32 \mathrm{~g}$ & $1.06 \pm 0.11 \mathrm{~cd}$ & $40.37 \pm 0.72 \mathrm{def}$ \\
\hline MET & 150 & $76.81 \pm 2.80$ ef & $0.87 \pm 0.13$ ef & $43.09 \pm 0.80 \mathrm{abc}$ & $81.66 \pm 3.44 \mathrm{ab}$ & $0.92 \pm 0.12 \mathrm{cde}$ & $42.31 \pm 0.72 \mathrm{abcd}$ \\
\hline MET & 225 & $82.85 \pm 4.30 \mathrm{abc}$ & $0.77 \pm 0.10 \mathrm{f}$ & $42.84 \pm 1.59 a b c$ & $82.15 \pm 1.05 \mathrm{ab}$ & $0.95 \pm 0.19 \mathrm{cde}$ & $42.96 \pm 0.83 \mathrm{abc}$ \\
\hline MET & 300 & $82.51 \pm 3.16 \mathrm{abcd}$ & $0.79 \pm 0.16 \mathrm{f}$ & $43.36 \pm 0.85 a b$ & $81.61 \pm 2.31 \mathrm{ab}$ & $0.90 \pm 0.24 \mathrm{cde}$ & $43.44 \pm 0.66 \mathrm{ab}$ \\
\hline PHE & 225 & $67.29 \pm 5.54 \mathrm{hi}$ & $1.02 \pm 0.10 \mathrm{de}$ & $38.30 \pm 1.74 \mathrm{f}$ & $67.07 \pm 6.88 \mathrm{fg}$ & $1.24 \pm 0.07 \mathrm{c}$ & $38.81 \pm 0.79 \mathrm{f}$ \\
\hline PHE & 375 & $77.62 \pm 2.14 \mathrm{def}$ & $0.82 \pm 0.04$ ef & $41.51 \pm 2.23 \mathrm{abcd}$ & $74.54 \pm 2.99 \mathrm{de}$ & $0.94 \pm 0.18 \mathrm{cde}$ & $40.79 \pm 0.96 \mathrm{cdef}$ \\
\hline MET + PHE (1:4) & $36+144$ & $70.04 \pm 1.49 \mathrm{gh}$ & $1.02 \pm 0.10 \mathrm{de}$ & $39.15 \pm 0.96 \mathrm{ef}$ & $71.09 \pm 1.56 \mathrm{ef}$ & $0.94 \pm 0.06 \mathrm{cde}$ & $39.40 \pm 1.04 \mathrm{ef}$ \\
\hline MET + PHE (1:4) & $48+192$ & $75.39 \pm 1.07 \mathrm{f}$ & $0.85 \pm 0.08$ ef & $41.19 \pm 1.32 \mathrm{bcde}$ & $76.27 \pm 0.94 \mathrm{~cd}$ & $0.85 \pm 0.08 \mathrm{de}$ & $41.26 \pm 0.99 \mathrm{bcde}$ \\
\hline MET + PHE (1:3) & $45+135$ & $73.29 \pm 0.92 \mathrm{fg}$ & $0.93 \pm 0.04$ ef & $40.13 \pm 0.92 \mathrm{def}$ & $74.97 \pm 1.61 \mathrm{de}$ & $0.85 \pm 0.05 \mathrm{de}$ & $40.75 \pm 1.26 \mathrm{cdef}$ \\
\hline MET + PHE (1:3) & $60+180$ & $81.77 \pm 0.40$ abcde & $0.72 \pm 0.04 \mathrm{fg}$ & $42.28 \pm 1.11 \mathrm{abcd}$ & $81.55 \pm 1.92 \mathrm{ab}$ & $0.73 \pm 0.07 \mathrm{de}$ & $42.03 \pm 0.87 \mathrm{abcd}$ \\
\hline MET + PHE (1:2) & $60+120$ & $78.40 \pm 1.06 \mathrm{cdef}$ & $0.90 \pm 0.03$ ef & $41.03 \pm 0.60 \mathrm{cde}$ & $78.38 \pm 2.00 \mathrm{bcd}$ & $0.77 \pm 0.13 \mathrm{de}$ & $41.81 \pm 0.43 \mathrm{abcd}$ \\
\hline MET + PHE (1:2) & $80+160$ & $86.01 \pm 1.61 \mathrm{a}$ & $0.52 \pm 0.10 \mathrm{~g}$ & $43.16 \pm 1.00 \mathrm{abc}$ & $83.87 \pm 0.97 \mathrm{a}$ & $0.74 \pm 0.18 \mathrm{de}$ & $43.97 \pm 0.86 \mathrm{a}$ \\
\hline MET + PHE (2:3) & $72+108$ & $80.75 \pm 1.48$ bcde & $0.82 \pm 0.06 \mathrm{ef}$ & $40.95 \pm 1.08 \mathrm{cde}$ & $80.20 \pm 0.83 \mathrm{abc}$ & $0.70 \pm 0.15 \mathrm{de}$ & $43.03 \pm 0.26 \mathrm{abc}$ \\
\hline MET + PHE (2:3) & $96+144$ & $85.27 \pm 1.12 \mathrm{ab}$ & $0.51 \pm 0.15 \mathrm{~g}$ & $43.70 \pm 0.92 \mathrm{a}$ & $84.81 \pm 0.98 \mathrm{a}$ & $0.59 \pm 0.05 \mathrm{e}$ & $43.16 \pm 2.07 \mathrm{ab}$ \\
\hline CAR & 750 & $44.08 \pm 4.95 \mathrm{j}$ & $4.21 \pm 0.28 \mathrm{~b}$ & $27.92 \pm 2.42 \mathrm{~g}$ & $49.25 \pm 4.00 \mathrm{i}$ & $4.02 \pm 0.18 b$ & $30.77 \pm 1.67 \mathrm{~g}$ \\
\hline CAR & 1,500 & $36.08 \pm 5.39 \mathrm{k}$ & $3.96 \pm 0.17 \mathrm{c}$ & $29.26 \pm 0.83 \mathrm{~g}$ & $54.80 \pm 1.94 \mathrm{~h}$ & $4.25 \pm 0.30 b$ & $32.73 \pm 3.26 \mathrm{~g}$ \\
\hline Water control & $\ldots$ & $\ldots$ & $7.14 \pm 0.26 \mathrm{a}$ & $24.37 \pm 2.03 \mathrm{~h}$ & $\ldots$ & $6.43 \pm 0.74 \mathrm{a}$ & $26.21 \pm 2.63 \mathrm{~h}$ \\
\hline Disease index & $\ldots$ & 36.77 & $\ldots$ & $\ldots$ & 34.12 & $\ldots$ & $\ldots$ \\
\hline
\end{tabular}

y Dose shown in grams of active ingredient per hectare. For FHB control, Fungicides represent the percentage of FHB control for the first 16 treatments, calculated as the rating for the treatment divided by the rating for the no-fungicide control $\times 100$. TGW $=$ thousand-grain weight. Values are the means \pm standard deviations of three replicate plots for each treatment. Means followed by different letters within the column are significantly different $(P<0.05)$ according to the least significant difference test.

${ }^{\mathrm{z}}$ MET, PHE, and CAR represent metconazole, phenamacril, and carbendazim, respectively.

\section{Untreated control \\ Carbendazim $1500 \mathrm{~g}$ a. i./ha a \\ Carbendazim $750 \mathrm{~g}$ a. i./ha}

Metconazole+Phenamacril $96+144 \mathrm{~g}$ a. i./ha Metconazole+Phenamacril $72+108 \mathrm{~g}$ a. i./ha Metconazole+Phenamacril $80+160 \mathrm{~g}$ a. i./ha Metconazole+Phenamacril $60+120 \mathrm{~g}$ a. i./ha Metconazole+Phenamacril $60+180 \mathrm{~g}$ a. i./ha Metconazole+Phenamacril $45+135 \mathrm{~g}$ a. i./ha Metconazole+Phenamacril $48+192 \mathrm{~g}$ a. i./ha Metconazole+Phenamacril $36+144 \mathrm{~g}$ a. i./ha Phenamacril $375 \mathrm{~g}$ a. i./ha Phenamacril 225g a. i./ha Metconazole $300 \mathrm{~g}$ a. i./ha Metconazole 225g a. i./ha Metconazole $150 \mathrm{~g}$ a. i./ha Metconazole $75 \mathrm{~g}$ a. i./ha

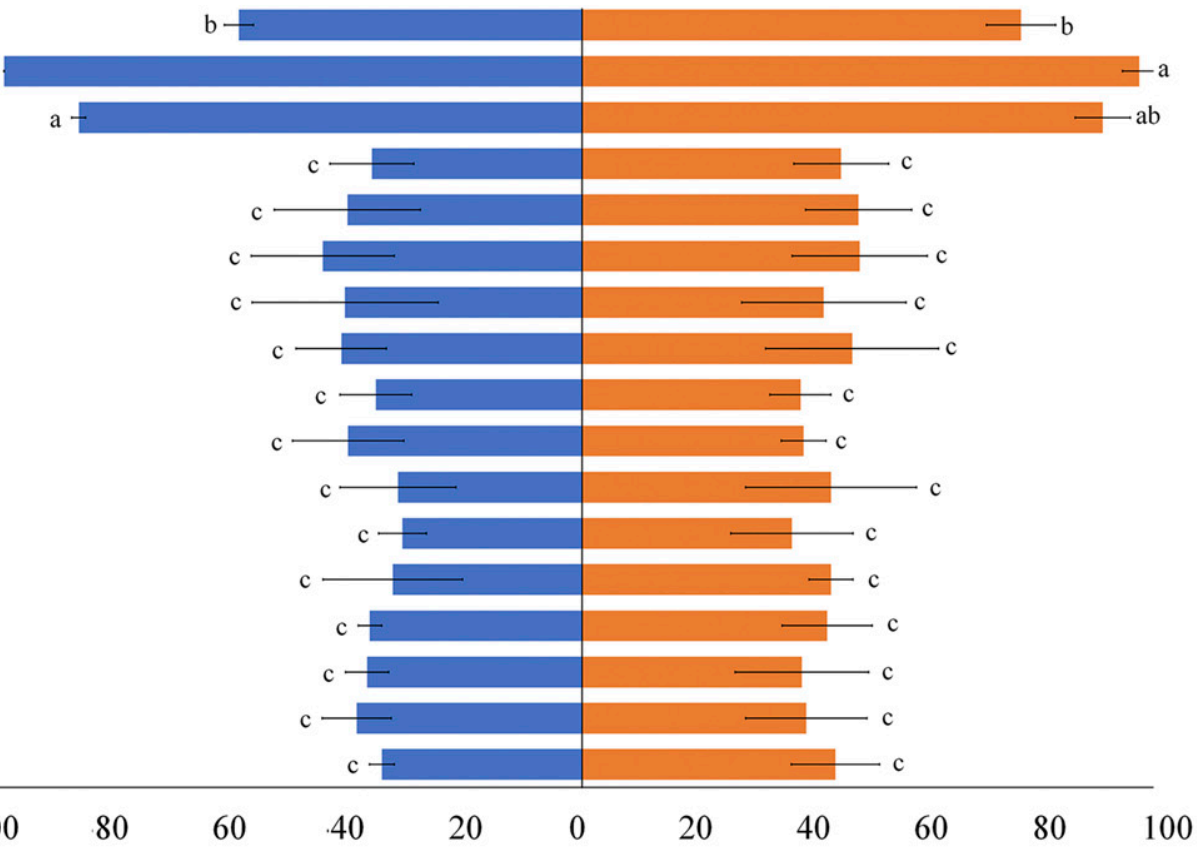

Carbendazim resistance frequence in 2015 (\%) Carbendazim resistance frequence in 2016 (\%)

Fig. 2. Impact of applications of metconazole and a mixture of metconazole and phenamacril on carbendazim-resistant allele frequencies in Fusarium graminearum populations in field trials. Mean values of three replicates \pm standard deviation. Different lowercase letters on columns indicate significant differences $(P<0.05)$ between treatments according to the least significant difference test. 
among the different populations and no significant difference was observed (Table 2). This indicated that metconazole had a strong inhibitory activity on either carbendazim-sensitive or -resistant strains and could be used to manage carbendazim resistance in F. graminearum.

Interactive effects of metconazole and phenamacril mixtures on mycelial growth. Carbendazim-sensitive strain S45 and carbendazim-resistant strain R49 were randomly selected from 67 strains for metconazole sensitivity and used to further determine interactive effects at the different ratios of metconazole and phenamacril. Based on the interactive effects of the mixture of metconazole and phenamacril on mycelial growth, SR values ranged from 0.91 to 1.39 for strain S45 (Table 3), and from 0.97 to 1.41 for strain R49 (Table 4). The results indicated that, in terms of mycelial growth inhibition, the interaction of metconazole and phenamacril at the tested ratios was additive for $F$. graminearum.
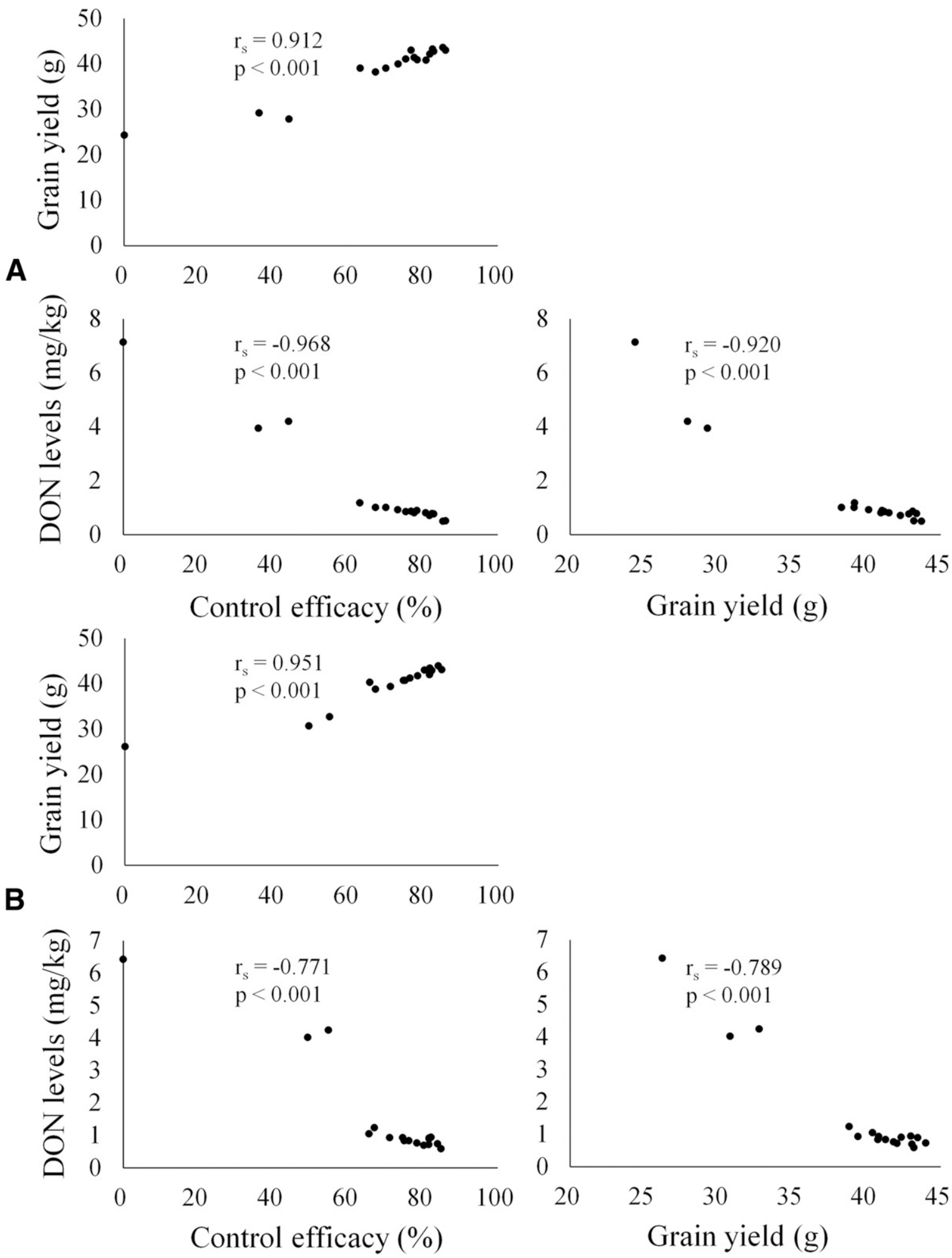

Fig. 3. Spearman's correlations between Fusarium head blight control, deoxynivalenol (DON) levels, and grain yields for different treatments $(n=17)$ in A, 2015 and B, 2016. $P<0.05$ means the correlation was statistically significant. 
Efficacy of metconazole and a mixture of metconazole and phenamacril on controlling FHB in wheat in field trials. The commonly used fungicides phenamacril and carbendazim were used as controls in the field trails. Control efficacy of metconazole in FHB increased with the increase of the dose (Table 5). Metconazole provided substantial control efficacy at dosages of 225 and $300 \mathrm{~g}$ a.i./ha in 2015 and at dosages of 150, 225, and $300 \mathrm{~g}$ a.i./ha in 2016 (Table 5). Phenamacril also controlled FHB but not as well as metconazole (Table 5). FHB control with carbendazim was significantly lower than all other treatments and did not differ between low and high dosages. This may be caused by a high frequency of carbendazim resistance in field populations of $F$. graminearum. These results indicated that metconazole had a good control efficacy for FHB and could be used for carbendazim resistance management in the field. In addition, under different ratios, control efficacy of the mixture of metconazole and phenamacril increased with the increase of dose. Compared with phenamacril alone, the mixture of metconazole and phenamacril not only exhibited better efficacy of FHB control but also decreased the doses of chemical compounds in the field. Among these treatments, the ratios $1: 2$ and 2:3 of metconazole/phenamacril at the dosage of $240 \mathrm{~g}$ a.i./ha exhibited the best efficacy of FHB control in both 2015 and 2016. Thus, the dosage of $240 \mathrm{~g}$ a.i./ha of the mixture of metconazole and phenamacril at the ratios $1: 2$ and 2:3 can be recommended for controlling FHB in the field in the future.

Evaluation of metconazole and a mixture of metconazole and phenamacril on reducing DON contamination in grain. In general, high disease indices of FHB led to high DON levels in wheat grain. In field trials, all fungicide treatments resulted in consistent reductions of DON levels in wheat kernels as compared with levels found in untreated control samples (Table 5). For all treatments, the variation trends for DON content values in 2 years were similar (Table 5). Metconazole at high dosages (150, 225, and $300 \mathrm{~g}$ a.i./ ha) and phenamacril at the highest dosage (375 a.i./ha) led to a significant reduction of DON content in kernels in comparison with the control fungicide carbendazim, and no significant differences were observed among the four treatments based on means from three plots. Compared with metconazole and phenamacril alone, the mixture of metconazole and phenamacril caused a significant reduction of DON content in kernels to some extent. For instance, both the ratios 1:2 and 2:3 of metconazole/phenamacril at high dosages had similar results, producing the greatest reduction of DON content in
Untreated control Carbendazim $1500 \mathrm{~g}$ a. i./ha Carbendazim $750 \mathrm{~g}$ a. i./ha Metconazole+Phenamacril $96+144 \mathrm{~g}$ a. i./ha Metconazole+Phenamacril $72+108 \mathrm{~g}$ a. i./ha Metconazole+Phenamacril $80+160 \mathrm{~g}$ a. i./ha A Metconazole+Phenamacril $60+120 \mathrm{~g}$ a. i./ha

A Metconazole+Phenamacril $60+180 \mathrm{~g}$ a. i./ha Metconazole+Phenamacril $45+135 \mathrm{~g}$ a. i./ha Metconazole+Phenamacril $48+192 \mathrm{~g}$ a. i./ha Metconazole+Phenamacril $36+144 \mathrm{~g}$ a. i./ha Phenamacril $375 \mathrm{~g}$ a. i./ha Phenamacril $225 \mathrm{~g}$ a. i./ha Metconazole $300 \mathrm{~g}$ a. i./ha Metconazole $225 \mathrm{~g}$ a. i./ha Metconazole $150 \mathrm{~g}$ a. i./ha Metconazole $75 \mathrm{~g}$ a. i./ha

90

Untreated control Carbendazim 1500g a. i./ha Carbendazim $750 \mathrm{~g}$ a. i./ha Metconazole+Phenamacril $96+144$ g a. i./ha Metconazole+Phenamacril $72+108 \mathrm{~g}$ a. i./ha Metconazole+Phenamacril $80+160 \mathrm{~g}$ a. i./ha

Metconazole+Phenamacril $60+120 \mathrm{~g}$ a. i./ha

Metconazole+Phenamacril $60+180 \mathrm{~g}$ a. i./ha Metconazole+Phenamacril $45+135 \mathrm{~g}$ a. i./ha Metconazole+Phenamacril $48+192 \mathrm{~g}$ a. i./ha Metconazole+Phenamacril $36+144 \mathrm{~g}$ a. i./ha Phenamacril $375 \mathrm{~g}$ a. i./ha Phenamacril $225 \mathrm{~g}$ a. i./ha Metconazole $300 \mathrm{~g}$ a. i./ha Metconazole $225 \mathrm{~g}$ a. i./ha Metconazole $150 \mathrm{~g}$ a. i./ha Metconazole $75 \mathrm{~g}$ a. i./ha 40
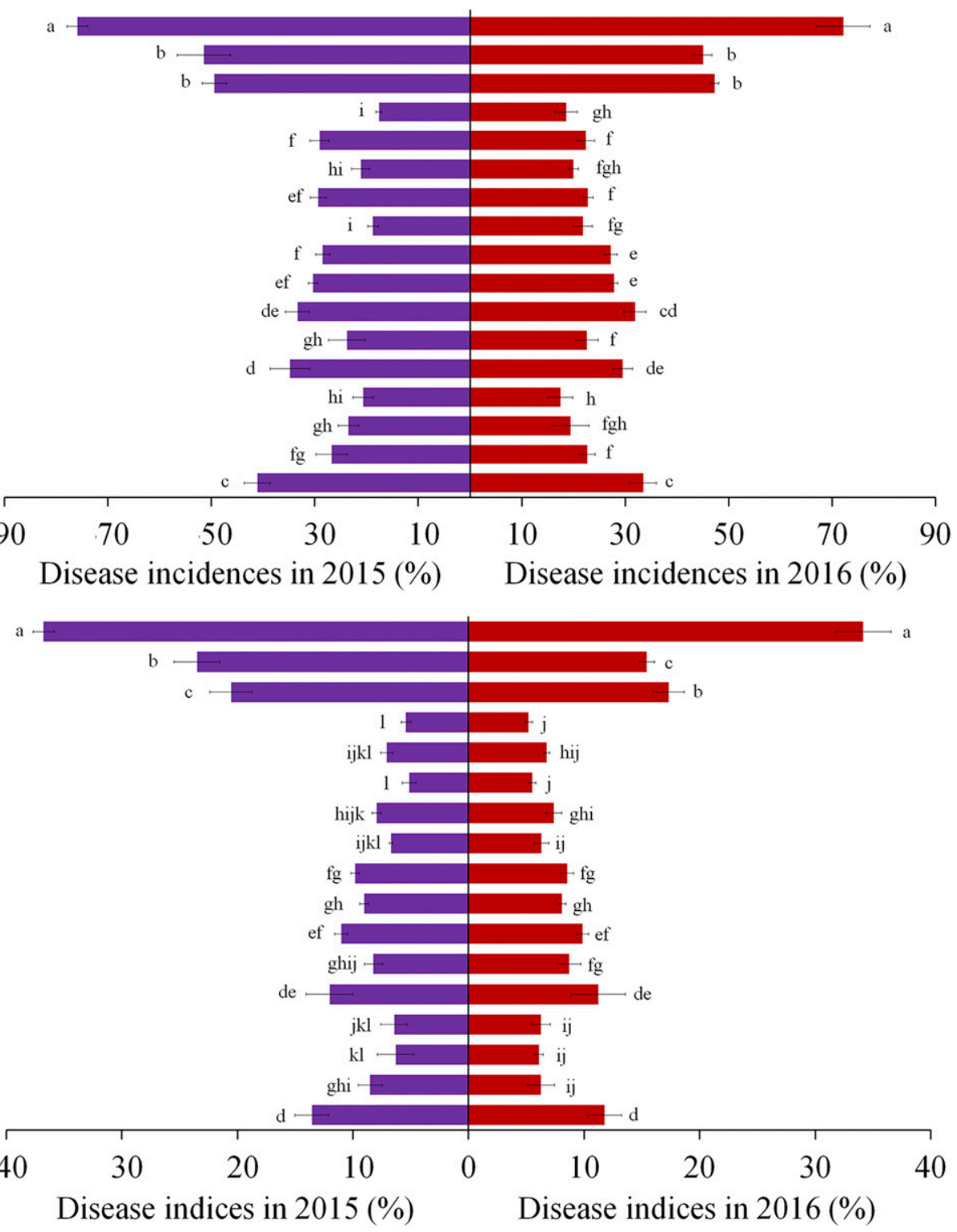

Fig. 4. Impact of applications of metconazole and a mixture of metconazole and phenamacril on A, disease incidences and B, indices in field trials in 2015 and 2016 . Mean values of three replicates \pm standard deviation. Different lowercase letters on columns indicate significant differences $(P<0.05)$ between treatments according to the least significant difference test. 
kernels in 2015, whereas the ratio 2:3 of metconazole/phenamacril at a high dosage led to the greatest reduction of DON content in kernels in 2016 (Table 5). Carbendazim treatments at low and high dosages did not differ in DON content, although they both reduced DON content in comparison with untreated controls in field trials from 2 years (Table 5).

Evaluation of metconazole and a mixture of metconazole and phenamacril on increasing grain yields. Compared with untreated controls, all of the fungicide treatments resulted in an increase in TGW values in field trials from 2 years (Table 5). Metconazole at a high dosage $(150,225$, and $300 \mathrm{~g}$ a.i./ha) led to a higher TGW than phenamacril at high dosages (375 a.i./ha), though these treatments did not differ in DON content in kernels. For the treatments with fungicide mixtures, variable significant differences of TGW were observed at different ratios and the variation trend of TGW was inconsistent in both years. The ratio 2:3 of metconazole/phenamacril at high dosage led to the greatest increase of TGW in 2015, whereas the ratio 1:2 of metconazole/ phenamacril at a high dosage led to the greatest increase of TGW in 2016. Carbendazim also showed slightly increased TGW values with respect to the untreated control. Nevertheless, these values were always inferior to those observed with other fungicide treatments (Table 5). This might be due to the high frequency of carbendazim-resistant populations in the field.

Effect of metconazole and a mixture of metconazole and phenamacril on carbendazim-resistant field populations of $\boldsymbol{F}$. graminearum. To assess the effect of metconazole and a mixture of metconazole and phenamacril on development of carbendazim resistance in field populations, we monitored the frequency of carbendazim-resistant F167Y $\beta$-tubulin alleles in each plot by the previously developed loop-mediated isothermal polymerase chain reaction assay (Duan et al. 2014). (Fig. 2) The dynamics of the measured carbendazim-resistant alleles in field populations sampled in 2 years were similar for the different fungicide treatments. The frequencies of carbendazim-resistant alleles in untreated control populations in 2015 and 2016 were 58.19 and $74.44 \%$, respectively.
Compared with untreated controls, the frequency of carbendazimresistant alleles significantly decreased in populations sampled after metconazole and phenamacril alone or the mixture of metconazole and phenamacril treatments, with frequencies decreasing to the lowest levels of 30.43 and $35.57 \%$ in 2015 and 2016, respectively. No significant differences in carbendazim-resistant allele frequencies were observed among metconazole and phenamacril alone or the mixture of metconazole and phenamacril treatments (Fig. 2). Significantly increased frequencies of carbendazim-resistant alleles were measured after carbendazim treatments, with highest frequencies of 97.97 and $94.51 \%$ measured in 2015 and 2016, respectively. This indicated that metconazole and a mixture of metconazole and phenamacril can be used for carbendazim-resistant management in $F$. graminearum in China.

Correlation between FHB control, grain yields, and DON production. To assess the correlation of between FHB control, grain yields, and DON production, Spearman's correlation analysis was performed with data from individual year. FHB control, grain yields, and DON production were highly correlated with each other (Fig. 3). As expected, a strong positive correlation was observed between FHB control and grain yields in both $2015(r=0.912)$ and $2016(r$ $=0.951)$ (Fig. 3). There were strong negative correlations for DON production and FHB control, and DON production and grain yield combinations at both farms $(r>0.771)$ (Fig. 3). This indicated that metconazole and a mixture of metconazole and phenamacril not only exhibited better efficacy in controlling FHB but also had increased grain yields and decreased DON contamination in grain in comparison with the currently used fungicides.

\section{Discussion}

The application of chemical compounds has always been a primary method for controlling FHB. Currently, carbendazim and phenamacril are extensively used fungicides for controlling FHB in China. Recently, carbendazim resistance in $F$. graminearum has been widely spread in China, especially in eastern China (Duan

2015
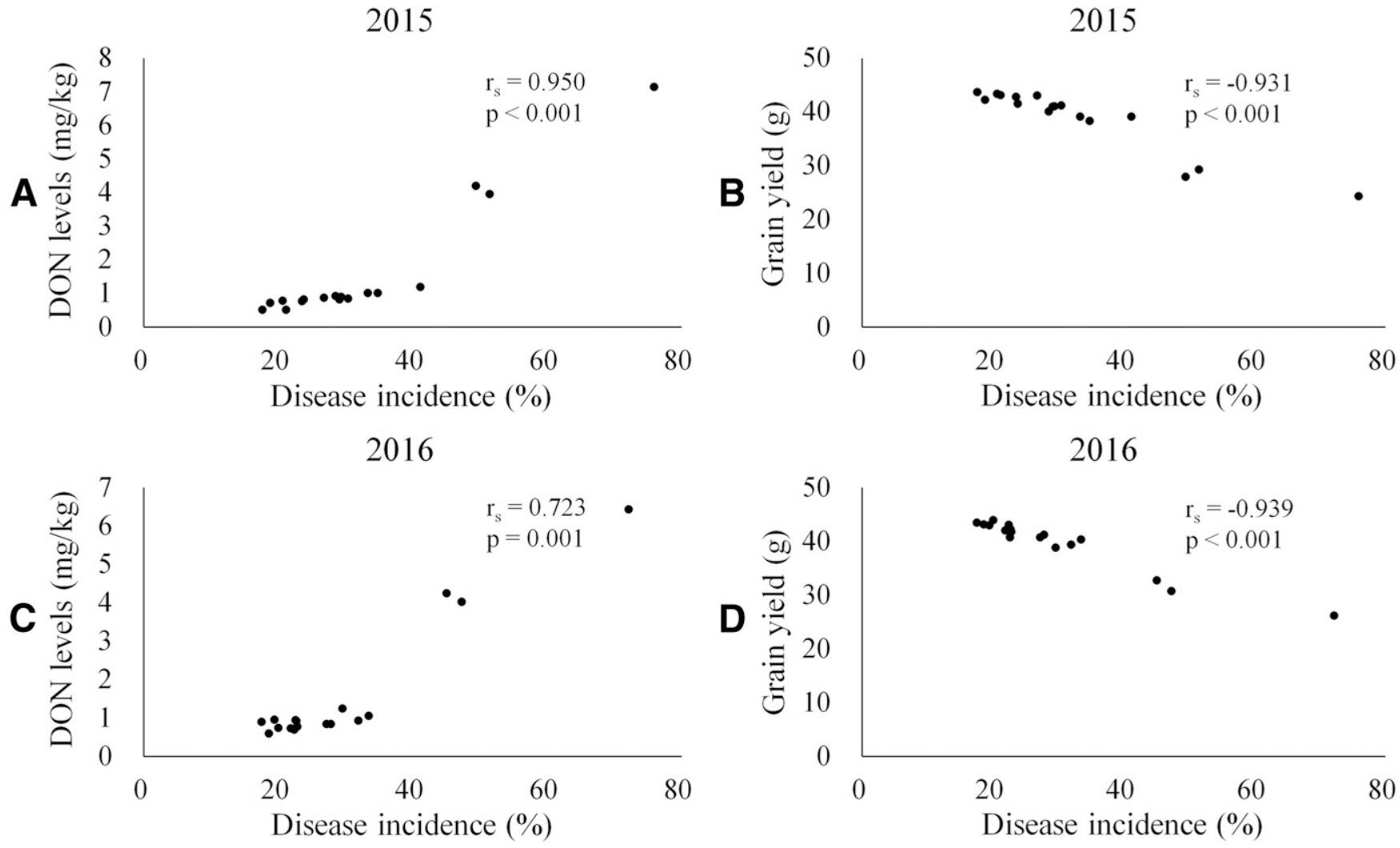

Fig. 5. Spearman's correlations between disease incidence and deoxynivalenol (DON) levels or grain yields for different treatments $(n=17)$ in $\mathbf{A}$ and $\mathbf{B}, 2015$ and $\mathbf{C}$ and $\mathbf{D}, 2016$. $P<0.05$ means the correlation was statistically significant. 
et al. 2014). Therefore, to manage carbendazim resistance of $F$. graminearum, baseline sensitivity to metconazole, a DMI fungicide, was evaluated for a selection of Chinese carbendazim-sensitive and -resistant strains using a mycelial growth inhibition assay. Moreover, the $\mathrm{EC}_{50}$ values of the two different groups of strains to metconazole showed no significant difference (Table 1). Tateishi et al. (2010) reported that the $\mathrm{EC}_{50}$ value of about $80 \%$ of the tested $F$. graminearum strains from Japan was $<0.1 \mu \mathrm{g} \mathrm{ml}{ }^{-1}$. Spolti et al. (2012) reported that the $\mathrm{EC}_{50}$ value of $F$. graminearum strains from Brazil ranged from 0.001 to $0.324 \mu \mathrm{g} \mathrm{ml}^{-1}$, with a mean $\mathrm{EC}_{50}$ value of $0.037 \mu \mathrm{g} \mathrm{ml}^{-1}$. The difference of metconazole sensitivity of FHB pathogens from different geographical regions might be due to the different geographically distributed species of FHB pathogens. Therefore, these data are essential for subsequent metconazole resistance monitoring and risk assessment of FHB pathogens in the future.

Phenamacril exhibits a specific activity against $F$. graminearum (Chen et al. 2008, 2011). However, high specificity of a fungicide also determines its high risk of resistance development. Previous study has shown that there was a high risk of phenamacril resistance development in Fusarium spp., including F. graminearum (Chen et al. 2011). Recently, phenamacril resistance in F. fujikuroi was confirmed in the field only 5 years after phenamacril was first used in China (Hou et al. 2018). To extend the service time of phenamacril in agriculture and reduce selection pressure of FHB pathogens to phenamacril in the field, the interactive effect of the mixture of metconazole and phenamacril on inhibiting mycelial growth was determined with carbendazim-sensitive and -resistant strains of $F$. graminearum. Unfortunately, the results from in vitro tests suggested that the mixture of metconazole and phenamacril at different ratios only exhibits an additive effect in $F$. graminearum based on mycelial growth. Though no synergistic effect in vitro was observed, the different ratios of metconazole and phenamacril with additive effect could still be used to control FHB in the field. Compared with phenamacril, metconazole exhibits a better activity on either mycelial growth in vitro or FHB control in planta. The registration dose of phenamacril in controlling FHB is $375 \mathrm{~g}$ a.i./ha (http://www.chinapesticide.org.cn/hysj/index.jhtml). Our findings showed that the suitable dose of metconazole in controlling FHB was $150 \mathrm{~g}$ a.i./ha. Thus, to further assess the potential of a mixture of metconazole and phenamacril in controlling FHB, reducing DON contamination and increasing grain yields, the ratios 1:4, 1:3, 1:2, and 2:3 of metconazole/phenamacril were used in field trials at Baimahu farm in 2015 and 2016. The extensively used fungicides phenamacril and carbendazim, both registered in China for controlling FHB, were used as controls to allow comparisons. All of the fungicide treatments decreased disease incidences (Fig. 4A), indices (Fig. 4B), and DON level, and increased grain yields in comparison with untreated controls (Table 5), although differences in efficacy of the treatments were observed in 2 years. Metconazole were significantly more effective than carbendazim in increasing FHB control and grain yields and reducing DON levels. These results are in agreement with other investigations about DMI fungicide applications, including prochloraz, tebuconazole, and prothioconazole (Bai et al. 2001; Doohan et al. 1996; Haidukowski et al. 2005; Homdork et al. 2000; Menniti et al. 2003; Paul et al. 2010, 2008; Simpson et al. 2001; Spolti et al. 2012). In addition, the efficacies of metconazole in FHB control, DON levels, and grain yields increased as dosage increased but similar results were observed for the three highest metconazole doses $(150,225$, and $300 \mathrm{~g}$ a.i./ha) in two experimental years. This indicated that metconazole at a dose of $150 \mathrm{~g}$ a.i./ha can reach better efficacies on FHB control, DON levels, and grain yields. Thus, we recommend $150 \mathrm{~g}$ a.i./ha of metconazole as a field application dosage for controlling FHB in the future. Furthermore, application of the mixture of metconazole and phenamacril at the different ratios were also tested in field trials. Compared with metconazole and phenamacril alone, the mixture of metconazole and phenamacril at ratios of 2: 3 and 1:2 not only exhibited excellent efficacy for FHB control, DON level, and grain yield (Table 5) but also decreased the dosage of phenamacril used in the field, reducing the risk of phenamacril resistance development. On the other hand, the mixture of metconazole and phenamacril at ratios of 2:3 and 1:2 reduced the risk of metconazole resistance development by decreasing the dosage of metconazole used in the field, although it had a higher dosage of chemical compounds than metconazole. Therefore, the mixture of metconazole and phenamacril will be a potential candidate for controlling FHB, decreasing DON contamination, and increasing grain yields in the future.

Previous studies reported a strong correlation of any two of FHB control, DON level, and grain yields (Haidukowski et al. 2005; Menniti et al. 2003; Simpson et al. 2001). In this study, the regression analysis was performed with data from individual years and strong correlations were also observed between FHB control and grain yields, FHB control and DON levels, and grain yields and DON levels in both experimental years (Fig. 3). In this study, FHB control efficacy was calculated based on disease indices. We further analyzed the correlation between disease incidence and DON levels or grain yields. Strong correlations were observed between disease incidence and DON levels, and disease incidence and grain yields, in both experimental years (Fig. 5). Similar results have also been reported with other fungicide applications (Bai et al. 2001; Haidukowski et al. 2005; Homdork et al. 2000; Menniti et al. 2003). This further confirmed that DON levels in grain were closely related to disease incidence or control efficacy, though DON production is regulated by many factors such as rainfall, temperature, available carbon or nitrogen source, and presence of other fungi (Gardiner et al. 2009a,b; Magan et al. 2002; Schmidt-Heydt et al. 2008).

Among all of the fungicide treatments, the lowest efficacies of carbendazim in FHB control, DON levels, and grain yields were observed and the efficacies did not differ between high and low doses of carbendazim. This can be explained by further selection for carbendazim resistance as measured by the increased frequency of carbendazim-resistant alleles. Interestingly, the carbendazimresistant allele frequency significantly decreased after metconazole and phenamacril alone and the mixture of metconazole and phenamacril applications in comparison with the untreated field populations. A previous study reported that carbendazim-resistant $F$. graminearum strains produced significantly more DON in grains in comparison with carbendazim-sensitive strains (Zhang et al. 2009). DON has been demonstrated to be an important virulence factor in $F$. graminearum (Cumagun et al. 2004; Desjardins et al. 2000; Goswami and Kistler 2005). Thus, at the beginning of wheat anthesis, carbendazim-resistant populations can infect wheat ears more rapidly in comparison with carbendazimsensitive populations. At this stage, application of chemical fungicides can better control FHB caused by carbendazim-resistant populations. This might be one of reasons why carbendazim-resistant allele frequency was decreased by metconazole and phenamacril alone and the mixture of metconazole and phenamacril. In addition, the decrease of DON contamination in grains affected by metconazole and a mixture of metconazole and phenamacril may be contributed by the decreased carbendazimresistant populations. Overall, the findings of the present work provide some novel insights into understanding the functions of fungicides in FHB control, DON contamination, grain yields, and development of drug-resistant Fusarium populations.

\section{Literature Cited}

Bai, G. H., Plattner, R., Desjardins, A., and Kolb, F. 2001. Resistance to Fusarium head blight and deoxynivalenol accumulation in wheat. Plant Breed. 120:1-6.

Bottalico, A., and Perrone, G. 2002. Toxigenic Fusarium species and mycotoxins associated with head blight in small-grain cereals in Europe. Eur. J. Plant Pathol. 108:611-624.

Chen, Y., Li, H., Chen, C., and Zhou, M. 2008. Sensitivity of Fusarium graminearum to fungicide JS399-19: In vitro determination of baseline sensitivity and the risk of developing fungicide resistance. Phytoparasitica 36:326-337.

Chen, Y., Wang, W., Zhang, A., Gu, C., Zhou, M., and Gao, T. 2011. Activity of the fungicide JS399-19 against Fusarium head blight of wheat and the risk of resistance. Agric. Sci. China 10:1906-1913.

Cumagun, C. J., Bowden, R. L., Jurgenson, J. E., Leslie, J. F., and Miedaner, T. 2004. Genetic mapping of pathogenicity and aggressiveness of Gibberella zeae (Fusarium graminearum) toward wheat. Phytopathology 94:520-526.

Dardis, J., and Walsh, E. J. 2000. Studies on the effectiveness of metconazole in controlling Fusarium head blight caused by Fusarium culmorum in spring wheat (Triticum aestivum L.). Cereal Res. Commun. 28:443-448. 
Desjardins, A. E., Bai, G., Plattner, R. D., and Proctor, R. H. 2000. Analysis of aberrant virulence of Gibberella zeae following transformation-mediated complementation of a trichothecene-deficient (Tri5) mutant. Microbiology 146:2059-2068.

Doohan, F. M., Nicholson, P., and Parry, D. W. 1996. Efficacy of the fungicides prochloraz and pyrimethanil against Fusarium culmorum ear blight of wheat. Pages 409-410 in: Brighton Crop Prot. Conf. Pests Dis..

Duan, Y., Ge, C., Liu, S., Chen, C., and Zhou, M. 2013. Effect of phenylpyrrole fungicide fludioxonil on morphological and physiological characteristics of Sclerotinia sclerotiorum. Pestic. Biochem. Physiol. 106:61-67.

Duan, Y., Liu, S., Ge, C., Feng, X., Chen, C., and Zhou, M. 2012. In vitro inhibition of Sclerotinia sclerotiorum by mixtures of azoxystrobin, SHAM, and thiram. Pestic. Biochem. Physiol. 103:101-107.

Duan, Y., Xiao, X., Li, T., Chen, W., Wang, J., Fraaije, B. A., and Zhou, M. 2018. Impact of epoxiconazole on Fusarium head blight control, grain yield and deoxynivalenol accumulation in wheat. Pestic. Biochem. Physiol. 152:138-147.

Duan, Y., Yang, Y., Wang, Y., Pan, X., Wu, J., Cai, Y., Li, T., Zhao, D., Wang, J., and Zhou, M. 2016. Loop-mediated isothermal amplification for the rapid detection of the F200Y mutant genotype of carbendazim-resistant isolates of Sclerotinia sclerotiorum. Plant Dis. 100:976-983.

Duan, Y., Zhang, X., Ge, C., Wang, Y., Cao, J., Jia, X., Wang, J., and Zhou, M. 2014. Development and application of loop-mediated isothermal amplification for detection of the F167Y mutation of carbendazim-resistant isolates in Fusarium graminearum. Sci. Rep. 4: Article 7094.

Gardiner, D. M., Kazan, K., and Manners, J. M. 2009a. Nutrient profiling reveals potent inducers of trichothecene biosynthesis in Fusarium graminearum. Fungal Genet. Biol. 46:604-613.

Gardiner, D. M., Osborne, S., Kazan, K., and Manners, J. M. 2009b. Low pH regulates the production of deoxynivalenol by Fusarium graminearum. Microbiology 155:3149-3156.

Gisi, U., Binder, H., and Rimbach, E. 1985. Synergistic interactions of fungicides with different modes of action. Trans. Br. Mycol. Soc. 85:299-306.

Goswami, R. S., and Kistler, H. C. 2005. Pathogenicity and in planta mycotoxin accumulation among members of the Fusarium graminearum species complex on wheat and rice. Phytopathology 95:1397-1404.

Haidukowski, M., Pascale, M., Perrone, G., Pancaldi, D., Campagna, C., and Visconti, A. 2005. Effect of fungicides on the development of Fusarium head blight, yield and deoxynivalenol accumulation in wheat inoculated under field conditions with Fusarium graminearum and Fusarium culmorum. J. Sci. Food Agric. 85:191-198.

Hao, J. J., Xie, S., Sun, J., Yang, G. Q., Liu, J. Z., Xu, F., Ru, Y. Y., and Song, Y. L. 2017. Analysis of Fusarium graminearum species complex from wheat-maize rotation regions in Henan (China). Plant Dis. 101:720-725.

Homdork, S., Fehrmann, H., and Beck, R. 2000. Effects of field application of tebuconazole on yield, yield components and the mycotoxin content of Fusarium-infected wheat grain. J. Phytopathol. 148:1-6.

Hou, Y. P., Qu, X. P., Mao, X. W., Kuang, J., Duan, Y. B., Song, X. S., Wang, J. X., Chen, C. J., and Zhou, M. G. 2018. Resistance mechanism of Fusarium fujikuroi to phenamacril in the field. Pest Manage. Sci. 74:607-616.

Ito, A., Saishoji, T., Kumazawa, S., and Chuman, H. 1999. Structure-activity relationships of the azole fungicide metconazole and its related azolylmethylcycloalkanols. J. Pestic. Sci. 24:262-269.

Levy, Y., Benderly, M., Cohen, Y., Gisi, U., and Bassand, D. 1986. The joint action of fungicides in mixtures: Comparison of two methods for synergy calculation. EPPO Bull. 16:651-657.

Li, M., Li, T., Duan, Y., Yang, Y., Wu, J., Zhao, D., Xiao, X., Pan, X., Chen, W., Wang, J., and Zhou, M. 2018. Evaluation of phenamacril and ipconazole for control of rice bakanae disease caused by Fusarium fujikuroi. Plant Dis. 102: 1234-1239.

Magan, N., Hope, R., Colleate, A., and Baxter, E. S. 2002. Relationship between growth and mycotoxin production by Fusarium species, biocides and environment. Eur. J. Plant Pathol. 108:685-690.
McMullen, M., Jones, R., and Gallenberg, D. 1997. Scab of wheat and barley: A reemerging disease of devastating impact. Plant Dis. 81:1340-1348.

Menniti, A. M., Pancaldi, D., Maccaferri, M., and Casalini, L. 2003. Effect of fungicides on Fusarium head blight and deoxynivalenol content in durum wheat grain. Eur. J. Plant Pathol. 109:109-115.

O’Donnell, K., Ward, T. J., Aberra, D., Kistler, H. C., Aoki, T., Orwig, N., Kimura, M., Bjørnstad, A., and Klemsdal, S. S. 2008. Multilocus genotyping and molecular phylogenetics resolve a novel head blight pathogen within the Fusarium graminearum species complex from Ethiopia. Fungal Genet. Biol. 45:1514-1522.

Parry, D., Jenkinson, P., and McLeod, L. 1995. Fusarium ear blight (scab) in small grain cereals: A review. Plant Pathol. 44:207-238.

Paul, P. A., Lipps, P. E., Hershman, D. E., McMullen, M. P., Draper, M. A., and Madden, L. V. 2008. Efficacy of triazole-based fungicides for Fusarium head blight and deoxynivalenol control in wheat: A multivariate meta-analysis. Phytopathology 98:999-1011.

Paul, P. A., McMullen, M. P., Hershman, D. E., and Madden, L. V. 2010. Meta-analysis of the effects of triazole-based fungicides on wheat yield and test weight as influenced by Fusarium head blight intensity. Phytopathology 100:160-171.

Placinta, C. M., D’Mello, J. P. F., and Macdonald, A. M. C. 1999. A review of worldwide contamination of cereal grains and animal feed with Fusarium mycotoxins. Anim. Feed Sci. Technol. 78:21-37.

Qiu, J., and Shi, J. 2014. Genetic relationships, carbendazim sensitivity and mycotoxin production of the Fusarium graminearum populations from maize, wheat and rice in eastern china. Toxins (Basel) 6:2291-2309.

Schmidt-Heydt, M., Magan, N., and Geisen, R. 2008. Stress induction of mycotoxin biosynthesis genes by abiotic factors. FEMS Microbiol. Lett. 284: 142-149.

Simpson, D. R., Weston, G. E., Turner, J. A., Jennings, P., and Nicholson, P. 2001 Differential control of head blight pathogens of wheat by fungicides and consequences for mycotoxin contamination of grain. Eur. J. Plant Pathol. 107:421-431.

Spolti, P., Jorge, B. C. D., and Ponte, E. M. D. 2012. Sensitivity of Fusarium graminearum causing head blight of wheat in Brazil to tebuconazole and metconazole fungicides. Trop. Plant Pathol. 37:419-423.

Tateishi, H., Miyake, T., Mori, M., Kimura, R., Sakuma, Y., and Saishoji, T. 2010. Sensitivity of Japanese Fusarium graminearum species complex isolates to metconazole. J. Pestic. Sci. 35:419-430.

Tateishi, H., Miyake, T., Mori, M., Sakuma, Y., and Saishoji, T. 2014. Effect of application timing of metconazole on Fusarium head blight development and mycotoxin contamination in wheat and barley. J. Pestic. Sci. 39:1-6.

Yli-Mattila, T., Gagkaeva, T., Ward, T. J., Aoki, T., Kistler, H. C., and O'Donnell, K. 2009. A novel Asian clade within the Fusarium graminearum species complex includes a newly discovered cereal head blight pathogen from the Russian Far East. Mycologia 101:841-852.

Yuan, S., and Zhou, M. 2005. A major gene for resistance to carbendazim, in field isolates of Gibberella zeae. Can. J. Plant Pathol. 27:58-63.

Zhang, H., Van der Lee, T., Waalwijk, C., Chen, W., Xu, J., Xu, J., Zhang, Y., and Feng, J. 2012. Population analysis of the Fusarium graminearum species complex from wheat in china show a shift to more aggressive isolates. PLoS One $7:$ e31722.

Zhang, L., Jia, X., Chen, C., and Zhou, M. 2013. Characterization of carbendazim sensitivity and trichothecene chemotypes of Fusarium graminearum in Jiangsu Province of China. Physiol. Mol. Plant Pathol. 84:53-60.

Zhang, Y. J., Yu, J. J., Zhang, Y. N., Zhang, X., Cheng, C. J., Wang, J. X., Hollomon, D. W., Fan, P. S., and Zhou, M. G. 2009. Effect of carbendazim resistance on trichothecene production and aggressiveness of Fusarium graminearum. Mol. Plant-Microbe Interact. 22:1143-1150.

Zhang, Y. J., Zhang, X., Chen, C. J., Zhou, M. G., and Wang, H. C. 2010. Effects of fungicides JS399-19, azoxystrobin, tebuconazole, and carbendazim on the physiological and biochemical indices and grain yield of winter wheat. Pestic. Biochem. Physiol. 98:151-157. 